\title{
Relief of YY1 transcriptional repression by adenovirus E1A is mediated by E1A-associated protein $\mathrm{p} 300$
}

\author{
Jeng-Shin Lee, ${ }^{1,2}$ Katherine M. Galvin,, ${ }^{1,5}$ Raymond H. See, ${ }^{1,5}$ Richard Eckner, $^{3}$ David Livingston, ${ }^{3}$ \\ Elizabeth Moran, ${ }^{4}$ and Yang $S i^{1,2,6}$ \\ ${ }^{1}$ Department of Pathology, ${ }^{2}$ Committee on Virology, Harvard Medical School, Boston, Massachusetts 02115 USA; ${ }^{3}$ Division \\ of Cellular and Molecular Biology, Dana-Farber Cancer Institute, Boston, Massachusetts 02115 USA; ${ }^{4}$ The Fels Institute \\ for Cancer Research and Molecular Biology, Temple University School of Medicine, Philadelphia, Pennsylvania 19140 USA
}

YY1 represses transcription when bound upstream of transcriptional initiation sites. This repression can be relieved by adenovirus E1A. Here, we present genetic evidence that the ability of E1A to relieve YY1 repression was impaired by mutations that affect E1A binding to its associated protein p300. This suggests that E1A may modulate the repressor activity of YY1 by binding to $\mathrm{p} 300$, which may be physically complexed with YY1. A YY1/p300 protein complex in vivo was demonstrated by several independent approaches, and the YY1-interacting domain was mapped to the carboxy-terminal region of p300, distinct from the E1A-binding site. Unlike E2F/RB, the YY1/p300 complex is not disrupted by E1A. Functional studies using recombinant p300 demonstrated unequivocally that p300 is capable of mediating E1A-induced transcriptional activation through YY1. Taken together, these results reveal, for the first time, a YY1/p300 complex that is targeted by E1A and demonstrate a function for p300 in mediating interactions between YY1 and E1A. Our data thus identify YY1 as a partner protein for p300 and uncover a molecular mechanism for the relief of YY1-mediated repression by $\mathrm{E} 1 \mathrm{~A}$.

[Key Words: Transcriptional repression; adenovirus E1A; YY1; p300; cofactor]

Received February 16, 1995; revised version accepted April 4, 1995.

Adenovirus ElA proteins are the first viral polypeptides synthesized after adenovirus infection (Lewis and Mathews 1980; Nevins 1981). The predominant forms of ElA proteins are encoded by the $12 \mathrm{~S}$ and the 13S E1A transcripts derived from differential splicing (Berk and Sharp 1978). Discrete regions in ElA that are highly conserved among different adenovirus serotypes have been identified as functionally important for the diverse biological activities of ElA (for review, see Shenk and Flint 1991). These functional domains are designated as conserved regions 1,2 , and 3 (CR1, CR2, CR3). CR1 and CR2 are common to both the $12 \mathrm{~S}$ and the $13 \mathrm{~S}$ E1A, whereas CR3 is unique to the 13S ElA (Kimelman et al. 1985). The E1A proteins are required for transcriptional activation of other adenoviral genes and are thus essential for the completion of the lytic cycle of the virus (Berk et al. 1979; Jones and Shenk 1979; Lewis and Mathews 1980; Nevins 1981). El A proteins have also been shown to activate other viral and cellular genes. Although the major transcriptional activation activity has been attributed to CR3 of the 13S E1A, 12S E1A can also activate transcrip-

\footnotetext{
${ }^{5}$ These authors contributed equally to this work. ${ }^{6}$ Corresponding author.
}

tion of a certain subset of promoters (Bagchi et al. 1990; Morris and Mathews 1991).

The mechanisms by which ElA activates transcription remain to be fully elucidated. However, a consensus is emerging that ElA may regulate transcription of its target genes via a mechanism involving protein-protein interactions. ElA has been shown to interact physically with the general transcription factor TATA-binding protein (TBP; Horikoshi et al. 1991; Lee et al. 1991) and with several DNA-binding transcription factors (Liu and Green 1990, 1994). In some instances, the functional interplay between ElA and transcription factors is mediated by ElA-associated proteins (for review, see Nevins 1992).

One of the targets of ElA is the transcription factor YY1 (Yin Yang 1) (Shi et al. 1991) (NF-E1, Park and Atchison 1991; $\delta$, Hariharan et al. 1991; UCRBP, Flanagan et al. 1992). YY1 is a zinc finger-containing transcription factor that is a member of the human GLI-Krüppel family of proteins (Ruppert et al. 1988). YYl represses or activates transcription, depending on the promoter context (for review, see Shrivastava and Calame 1994). Both repression and activation domains have been identified within YY1, which provides a structural basis for its dual functionality (Lee et al. 1994; Lee et al. 1995). A large number of cellular and viral genes have been shown to be 
negatively regulated by $\mathrm{YY} 1$, including genes that are important in differentiation (for review, see Shrivastava and Calame 1994). Examples of genes positively regulated by YY1 include c-myc (Riggs et al. 1993) and certain ribosomal protein genes (Hariharan et al. 1991).

YY1-binding sites were initially identified in the adeno-associated virus $\mathrm{P} 5$ promoter whose activity was repressed by YY1 (Chang et al. 1989). This repression can be relieved by adenovirus $\mathrm{ElA}$, and further activation of P5 promoter transcription occurs /Chang et al. 1989; Shi et al. 1991). These observations were recapitulated by GAL4 fusion protein-based assays in which GAL4-YY1mediated transcriptional repression was shown to be relieved by ElA (Shi et al. 1991). However, the mechanisms underlying the ability of E1A to relieve YY1 repression were not clear. In this report we have analyzed the ability of ElA proteins carrying mutations in the functional domains to relieve YY1 repression. Our results have demonstrated clearly that relief of YY1 repression by E1A is dependent on the ability of EIA to bind its associated protein p300 (Whyte et al. 1989; Wang et al. 1993/. p300 was originally identified in a coimmunoprecipitation assay as a cellular protein that interacts with ElA (Yee and Branton 1985; Harlow et al. 1986). It is related to the coactivator CREB-binding protein (CBP) that binds activated CREB transcription factor /Chrivia et al. 1993; Arany et al. 1994; Arias et al. 1994; Eckner et al. 1994; Kwok et al. 1994) and is likely involved in the regulation of cell growth and differentiation (Jelmsa et al. 1989; Wang et al. 1993; Slack et al. 1995). However, the partner proteins for p300 and its precise mode of functions are unknown.

The above genetic study of the functional domains of ElA involved in relieving YYl repression suggested the existence of $\mathrm{YY} 1 / \mathrm{p} 300$ complexes in vivo. Using biochemical and immunological assays, we demonstrated the presence of a YY $1 / \mathrm{p} 300$ complex in vivo. In vitro, YY1 and p300 can directly interact with each other. Significantly, we showed that overexpression of p300 activates YY1-mediated transcription in the presence of E1A, whereas a mutant p300 unable to interact with E1A failed to do so. This reinforces the notion that p300 is an important cofactor that connects ElA to DNA-bound YY1. Glutathione $S$-transferase (GST) affinity chromatography and coimmunoprecipitation assays indicated that YY1 and E1A both bind to the carboxy-terminal region of $\mathrm{p} 300$, but their binding sites are distinct. These data suggested that YY1 and ElA may bind to the same p300 molecule simultaneously. We investigated the status of the YY1/p300 complex in adenovirus-infected HeLa cells and found that the level of the complex was comparable to that in uninfected cells. This is consistent with the possibility that E1A may bind YY1/p300 to form a tripartite complex, in contrast to the E2F/RB complex, which has been shown to be dissociated by E1A.

In summary, our results have uncovered for the first time a molecular mechanism for the relief of YY1-mediated repression by E1A. At the same time, we have identified YY1 as a partner for $\mathrm{p} 300$ and a function for p300 as a cofactor that bridges E1A to YY1.

\section{Results}

Specific functional interactions between YY1 and adenovirus E1A

The functional interactions between YY1 and adenovirus E1A can be recapitulated by GAL4 fusion proteinbased assays (Shi et al. 1991). As shown in Figure 1, GAL4-YY1 repressed the CAT activity in a dose-responsive manner (cf. lanes 2 and 3 with lane 1). E1A, but not its frameshift mutant, relieved YY1 repression (Fig. 1, cf. lanes 4-7 with lane 1). To determine the specificity of this ElA effect, another zinc finger-containing transcriptional factor WT1 (Wilms' tumor $\underline{1}$ ) was examined (Call et al. 1990; Madden et al. 1991). GAL4-WT1 effectively repressed the activity of the GAL4-thymidine kinase (TK) promoter (Fig. 1, cf. lanes 8 and 9 with lane 1) as reported (Madden et al. 1991). However, the repressor function of GAL4-WT1 was unaffected by E1A (Fig. 1, cf. lanes 10 and 11 with lane 9|. Taken together, these data indicate a specific functional interaction between YY1 and E1A.

The p300-binding domain of E1A is necessary for E1A to relieve YY1 repression

To understand the mechanisms underlying the ability of E1A to relieve transcriptional repression by YYl, we car-

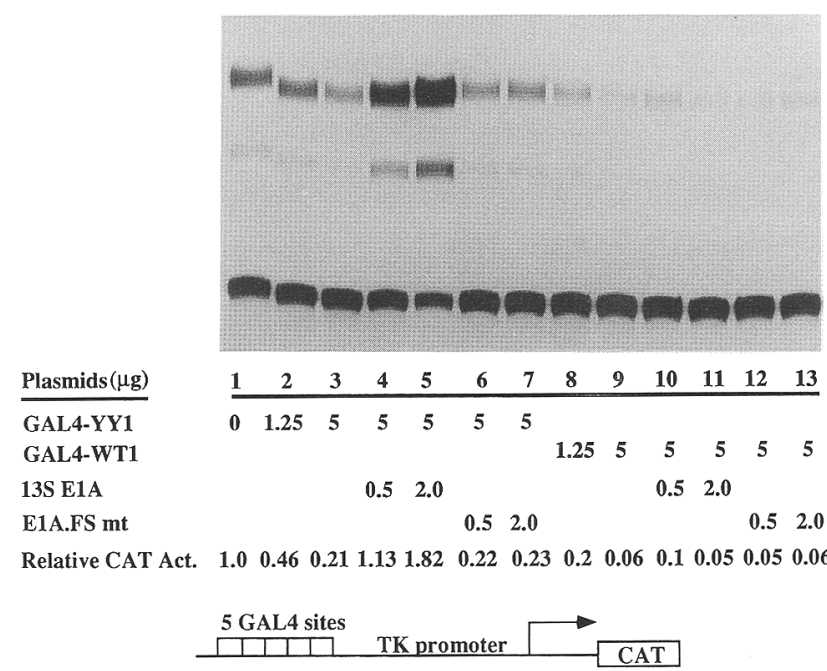

Figure 1. The effect of adenovirus E1A on the repressor activity of YYl is specific. pGAL4-YYl or pGAL4-WT1 containing the entire coding region of YYl or WT1 cDNAs was transfected into HeLa cells together with the reporter plasmid pGAL4TK-CAT in the presence or absence of a plasmid encoding the 13S ElA protein or an ElA frameshift mutant plasmid (for detailed description of all the constructs, see Materials and methods). The amount of transfected plasmid DNAs and the combination of plasmids used in each transfection are indicated. The extent of acetylation in various reactions was determined relative to that for pGAL4-TKCAT transfected alone. The relative CAT activity reported as 1 represents an average CAT conversion of $30 \%$. CAT assay results (average of three experiments) are shown at the bottom. 
ried out experiments to identify domains of E1A that were involved in this process. ElA mutants with gross deletions that disrupted the functional domains (CR1, $\mathrm{CR} 2$, and the amino-terminal domain) were analyzed. A representative chloramphenicol acetyltransferase (CAT) assay autoradiograph is shown in Figure $2 \mathrm{~A}$, and the results are summarized in Figure 2C. As shown in Figure 2A, wild-type ElA, but not the frameshift mutant of ElA, relieved repression (Fig. 2A, lanes 2,3,9). Deletion of the amino-terminal 36 amino acids of the $12 \mathrm{~S}$ or the 13S ElA completely abolished their ability to alter the repressor activity of YY1 (Fig. 2A, cf. lanes 4 and 6 with lanes 3 and 5). Similarly, deletion of CR1 virtually eliminated the effect of E1A on YY1 (Fig. 2A, lane 7). In contrast, deletion of CR2 essentially had no effect as it retained $74 \%$ of the wild-type $12 \mathrm{~S}$ E1A activity (Fig. 2A, lane 8 ). These results indicated the importance of the amino-terminal region as well as CR1 in relieving repression mediated by YY1. The amino-terminal domain and CR1 of E1A are involved in the binding of cellular proteins $\mathrm{p} 300$ and retinoblastoma protein (RB) family mem- bers (Whyte et al. 1989; Wang et al. 1993). As shown below, it is likely that RB and its related proteins are not involved in this biochemical pathway leading to relief of YYl-mediated repression by E1A in HeLa cells.

Because analysis of the ElA deletion mutants suggested the importance of the amino-terminal region of E1A, mutants with single amino acid substitutions in this region were examined. RG2, HN3, and LS20 all harbor single amino acid substitutions at positions 2, 3 and 20 , respectively. These mutants exhibit impaired abilities to bind $\mathrm{p} 300$ but bind the RB family of proteins like wild-type E1A (Whyte et al. 1989; Wang et al. 1993). Functionally, all three mutants had greatly reduced abilities to relieve YY1-mediated repression (Fig. 2B, lanes 4-6). In contrast, single amino acid substitutions within $\mathrm{CR} 1$ and CR2 (pm47/124) that impaired binding of E1A to the RB family of proteins had virtually no effect on the ability of the mutant to relieve repression by YY1 (Fig. 2B, lane 7). The expression of the mutant proteins in the same lysates used for CAT assays was examined by Western blotting using $\alpha$-ElA antibodies (Whyte et al.
Figure 2. The amino-terminal region of ElA is necessary to relieve YYl-mediated transcriptional repression. $(A, B)$ Plasmid DNAs were transfected into HeLa cells for analysis of the E1A domains required for relief of YY1-mediated repression. Representative CAT assay autoradiographs are shown. The ElA mutants used in each transfection reaction are indicated at the top. The results are summarized in $C$. In addition, schematic diagrams of wild-type and various deletion mutants of ElA used in the experiments are shown. Locations of CR1, CR2, and CR3 within E1A are indicated. The abilities of various E1A proteins to bind pRB, pl07, and p300 are indicated $1+$ or -1 . Weak binding is indicated $(+1-1$ ) data taken from Whyte et al. 1989; Wang et al. 1993). Quantitative analyses of the CAT assay results from $A$ and $B$ are presented with mean \pm S.D. from three independent transfections. (ND) Not determined.

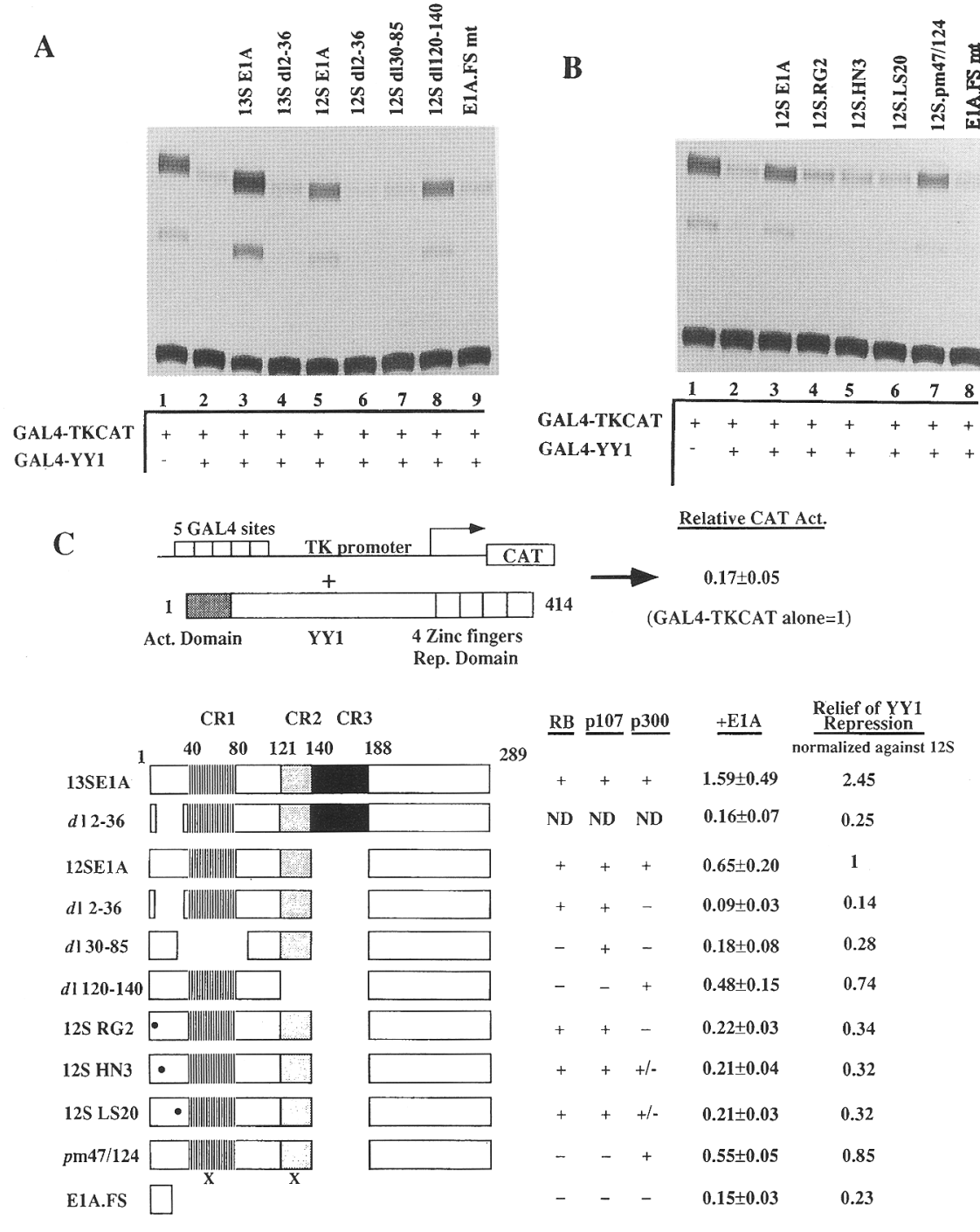


1989). The steady-state levels of the wild-type and the mutant E1A proteins were found to be comparable /data not shown). These observations suggest that in HeLa cells, p300 but not RB and/or its related proteins are involved in the relief of YY1-mediated repression by E1A.

To confirm the results, another reporter, GAL4E1BCAT, was examined. GAL4-E1BCAT contains the minimal adenovirus E1B promoter that exhibits very low levels of activity (Lillie and Green 1989). Therefore, the repressor function of YYl is not readily detectable with this reporter. However, it provides another promoter context to study the functions of YY1 and the ability of E1A to induce transcriptional activation through YY1. As shown in Figure 3, the 13S E1A, but not the frameshift mutant, activated GAL4-E1BCAT in the presence of GAL4-YYl (Fig. 3, lanes 1,2), consistent with the data obtained using the GAL4-TKCAT reporter plasmid described above. The activation is dependent on YY1 because E1A alone has no effects on GAL4-E1BCAT (Liu and Green 1994; data not shown). Interestingly, 13S E1A-carrying deletion or point mutations in the aminoterminal region all manifested an impaired ability to activate YY1-mediated transcription (Fig. 3, lanes 3-6). In contrast, a point mutant at amino acid 47 (abolishes RB binding) in 13S ElA virtually had no effect on activation through YY1 (Fig. 3, lane 7). Western blot analysis showed that all mutants expressed comparable levels of E1A proteins as wild-type $13 \mathrm{~S}$ in the transfected cells
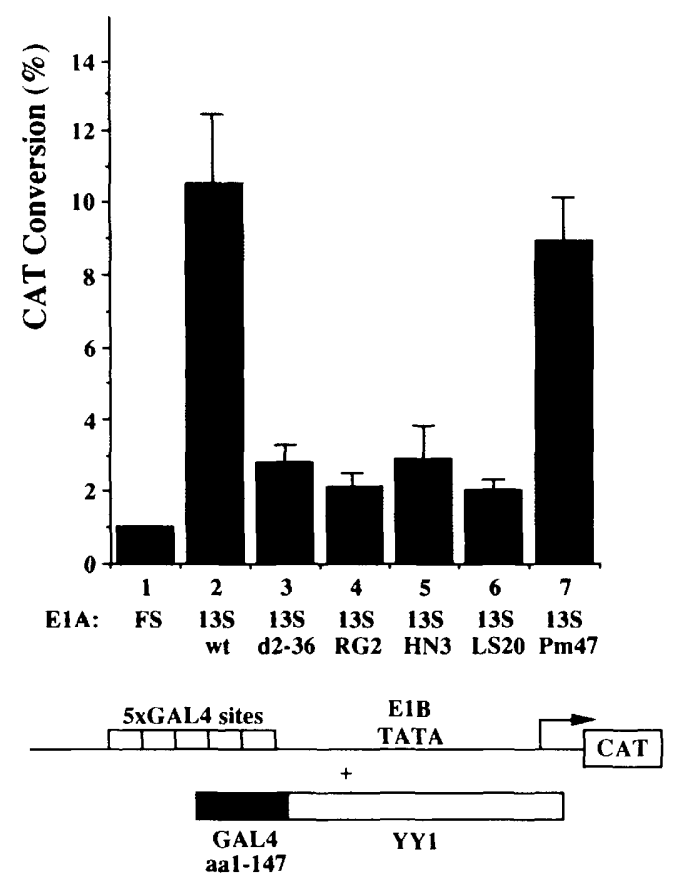

Figure 3. The amino-terminal region is essential for 13S E1A to further activate YYl-mediated transcription. Ten micrograms of pGAL4-E1BCAT and $5 \mu \mathrm{g}$ of pGAL4-YY1 were transfected into HeLa cells together with $2 \mu \mathrm{g}$ of expression vectors encoding an E1A frameshift mutant plasmid, wild type, or mutants of $13 \mathrm{~S}$ E1A as indicated. The results represent the average of three independent transfections and CAT assays. (data not shown). These results suggest that further activation of YYl-mediated transcription by 13S E1A /Shi et al. 1991; this study) is also dependent on p300 binding, and CR3 alone cannot induce activation through YYl.

\section{Evidence for physical interactions between YY1 and $p 300$}

Identification of the p300-binding domain of E1A as the critical element for relieving YY1-mediated repression suggested the involvement of $\mathrm{p} 300$ in this process. By analogy to the E2F paradigm in which E1A activates E2F by binding to $\mathrm{RB}$ that is physically complexed with $\mathrm{E} 2 \mathrm{~F}$ (Nevins 1991, 1992; Dyson and Harlow 1992), one may hypothesize that ElA modulates the activity of YY1 by binding to p300, which may be complexed with YY1. Immunoprecipitation/Western blotting experiments were carried to determine whether YY1 and p300 interact physically in vivo. HeLa whole cell extracts were incubated with a polyclonal antibody against YYl or with rabbit preimmune antibodies as a control. The immunoprecipitates were separated by SDS-PAGE, blotted, and probed with $\alpha-$ p300 monoclonal antibodies (Eckner et al. 1994). To facilitate localization of p300 on the blot, 293 whole cell extracts were incubated with $\alpha$-E1A antibody M73 (Whyte et al. 1989). As shown in Figure 4A, p300 is visible in the immunocomplex brought down by the $\alpha$-YYl antibody (lane 2, HeLa cells) as well as by the $\alpha$-E1A antibody M73 (lane 4, 293 cells) but not in the complex brought down by the rabbit or mouse preimmune antibodies (Fig. 4A, lanes 1,3). To ensure that the presence of the $\mathrm{p} 300$ protein in the YY1 immunocomplex is specific, the same blot was reprobed with an antibody against the E1A-associated protein p107 (Dyson et al. 1993). As shown in Figure 4B, p107 was brought down by M73 from 293 cells (lane 4), as expected, but not by $\alpha-Y Y 1$ antibodies from HeLa cells (lane 2). These observations suggest that $\mathrm{YY} 1$ interacts physically with $\mathrm{p} 300$ but not with RB family proteins. This is consistent with the results from functional studies described above suggesting that the RB family of proteins were not involved in relief of YY1-mediated repression by E1A in HeLa cells.

The reciprocal immunoprecipitation/Western experiment was also performed using $\alpha$-p300 monoclonal antibodies to coimmunoprecipitate YY1. As shown in Figure $4 \mathrm{C}, \mathrm{YYl}$ is detected in the immunocomplex brought down by $\alpha$-p300 antibodies (lane 3) but not by normal mouse serum (lane 2). The prominent bands in lanes 2 and 3 represent immunoglobulin proteins from the immunoprecipitation reactions that are recognized by goat $\alpha$-rabbit antibodies in the subsequent Western assay. To ascertain the specificity of the immunoprecipitation/ Western reactions, competition experiments were performed using bacterially purified GST or GST-YY1 proteins. As shown in Figure 4C (right), the level of endogenous YY1 coprecipitated by $\alpha-p 300$ antibodies was reduced in the presence of GST-YY1, accompanied by the appearance of GST-YY1 (Fig. 4C, cf. lanes 5 and 6). This experiment further confirmed that the band detected by affinity-purified $\alpha$-YYl polyclonal antibodies (Fig. 4C, lane 3 ) is most likely YY1. The interaction be- 


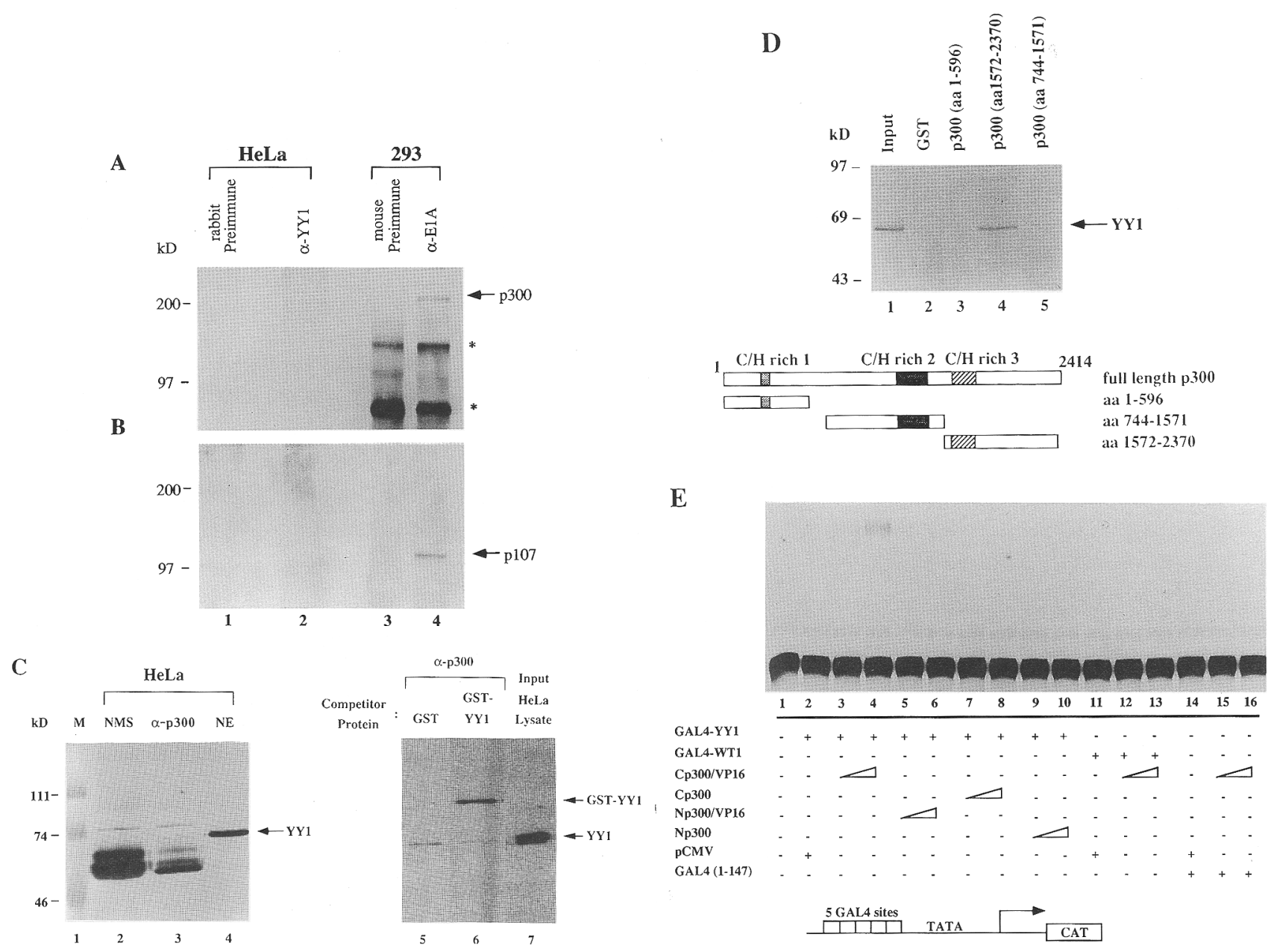

Figure 4. Physical interactions of YYl and p300. Top panel $(A) \mathrm{p} 300$ immunoblot analysis of immunoprecipitates from HeLa or 293 cells obtained with rabbit preimmune serum (lane 1), $\alpha$-YYl polyclonal antibody (lane 2), normal mouse serum (lane 3), or $\alpha$-E1A monoclonal antibody M73 (lane 4). The position of the p300 is indicated by an arrow at right. Molecular mass markers are shown at left. Asterisks (*) indicate nonspecific bands present in both preimmune and immune serum. $(B)$ p 107 immunoblot analysis of the same immunoprecipitates from $A$. $(C$, left $)$ YY 1 immunoblot analysis of immunoprecipitates from HeLa cells obtained with normal mouse preimmune serum (lane 2) and $\alpha$-p300 monoclonal antibodies (lane 3). The position of YYl is shown using HeLa nuclear extracts (lane 4) and is indicated by an arrow at right. Molecular mass markers are shown at left. (C, right) YYl immunoblot analysis of $\alpha$-p300 immunoprecipitates from HeLa cell lysates preincubated with purified GST (lane 5) or GST-YY1 (lane 6). The position of YY 1 is shown using the input HeLa cell lysate (lane 7) and is indicated by an arrow at right. The position of GST-YY1 is also indicated. (D) Interaction of endogenous YYl with various GST-p300 deletion mutants. HeLa nuclear extracts were incubated with GST-p300 mutants consisting of the amino-terminal, carboxy-terminal, and central portions of the protein (lanes 3-5) or with GST moiety alone (lane 2). The bound YY1 protein was visualized by immunoblot analysis using $\alpha$-YY1 antibodies. YY1 is indicated by an arrow at right. Molecular mass markers are shown at left. (Lane 1) Input HeLa nuclear extract. (E) Two-hybrid assays of YY1/p300 interactions in vivo. Different combinations of expression vectors were cotransfected into HeLa cells with the reporter GAL4-ElBCAT as indicated $1+$ or -1 .

tween YY1 and p300 was also demonstrated using a GST affinity matrix-based assay (Kaelin et al. 1991). HeLa extracts were incubated with GST-p300 affinity beads, and the bound YYl proteins were visualized by Western blot analysis using $\alpha$-YY1 monoclonal antibodies. As shown in Figure 4D, YY1 was captured by the carboxy-terminal (amino acids 1572-2370) but not by the amino-terminal (amino acids 1-596) or the central portions of the p300 protein (amino acids 744-1571), suggesting that the carboxy-terminal region contains an element important for YY1 binding (Fig. 4D).

To ascertain that YY1 and p300 interact physically in vivo, two-hybrid assays were carried out in HeLa cells (Fields and Song 1989; Lillie and Green 1989). As shown in Figure 4E, the carboxy-terminal region of p300 /amino acids 871-2377), when fused to herpes simplex virus (HSV) VP16 activation domain (Cp300/VP16), activated GAL4-E1BCAT in a dose-responsive manner, dependent on the presence of the GAL4-YYl proteins (lanes 3,4). This activation requires binding of GAL4-YY1 to the promoter, because the same target gene lacking the GAL4 sites was not responsive to Cp300/VP16 /data not shown). The same Cp300/VP16 fusion protein did not affect the GAL4 DNA-binding domain alone (lanes 
15,16) or GAL4-WT1 (lanes 12,13)-mediated transcription. Furthermore, the $\mathrm{N}$ terminal region of $\mathrm{p} 300$ (amino acids 1-1275) fused to the VP16 activation domain (Np300/VP16) did not support GAL4-YY1-mediated activation of the GAL4-E1BCAT reporter (lanes 5,6). Taken together, the results suggest in vivo $\mathrm{YY} 1 / \mathrm{p} 300$ interaction, and the importance of the carboxy-terminal region of $\mathrm{p} 300$ in this interaction. These findings are consistent with those obtained in the immunoprecipitation/ Western and the GST affinity matrix assays described earlier.

It is possible that the in vivo $\mathrm{YY} 1 / \mathrm{p} 300$ interaction may be mediated by other proteins. To determine whether YY1 and p300 directly interact, bacterially purified His-tagged YY1 (Shi et al. 1991) was incubated with purified GST-p300 (amino acids 1572-2370) attached to glutathione-agarose beads. As shown in Figure 5, substantial amounts of His-YYl were captured by the GST-p300 affinity column (lane 4) but not by GST alone (lane 3), suggesting that YY1 and p300 can interact directly in vitro.

\section{p300 activates YY1-mediated transcription in the presence of $E 1 A$}

The genetic study demonstrating the importance of p300 in the relief of YY1 repression by E1A, together with the identification of the YY1/p300 complex in vivo, suggested strongly that p300 is the mediator between YYl and E1A. To demonstrate directly that p300 mediates the effect of E1A on YY1, CAT reporter plasmids under the control of either wild-type (pP5-60CAT) or mutant [pP5-60(mt2)CAT] YY1-binding sites (Shi et al. 1991) were cotransfected with p300 expression plasmids into 293 cells that constitutively express ElA /Graham et al. 1977). As shown in Figure 6, wild-type p300 increased CAT activity from pP5-60CAT but not from pP560 (mt2)CAT, suggesting that p300 activated transcription through YY1, in the presence of E1A /cf. lanes 2 and 3 with lanes 7 and 8 ). In contrast, the mutant p300 dl10 that fails to bind El A (Eckner et al. 1994; R. Eckner and D. Livingston, unpubl.) was unable to induce CAT ac-

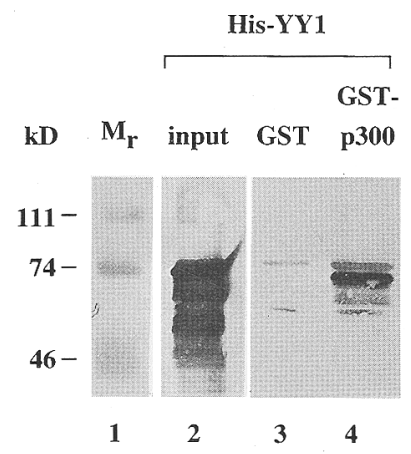

Figure 5. YYl and p300 directly interact in vitro. Bacterially purified His-YY1 was incubated with GST (lane 3) or GST-p300 amino acids 1572-2370; (lane 4). The bound YYl protein was visualized by immunoblot analysis using $\alpha$-YYl antibodies. The input lane (lane 2) represents $25 \%$ of the His-YY1 used in the binding reactions. (Lane 1) molecular weight markers.

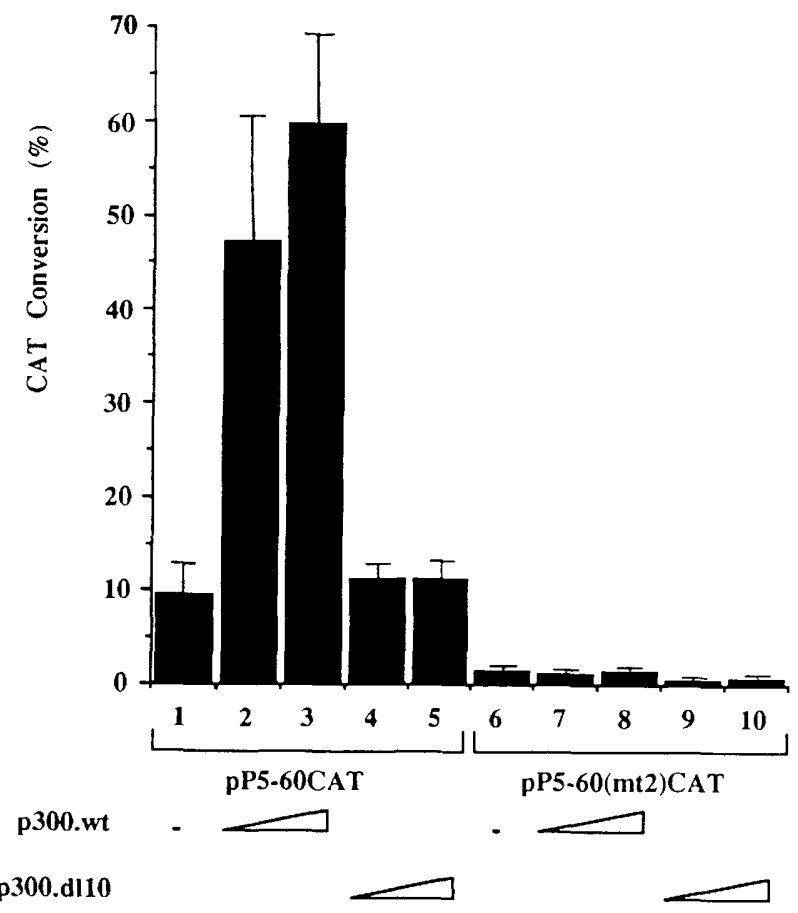

Figure 6. The wild-type but not the mutant p300 defective for ElA binding activates transcription through YY1-binding sites in the presence of ElA. Plasmid DNAs were transfected into 293 cells and extracts were prepared for CAT assays. The results are shown as bar graphs with mean \pm S.D. from three independent transfections. Each transfection contained $4 \mu \mathrm{g}$ of target plasmid and 2 or $6 \mu \mathrm{g}$ of wild-type or mutant p300 plasmid.

tivity from pP5-60CAT (Fig. 6, lanes 4,5), indicating that the activation induced by $\mathrm{p} 300$ requires the participation of E1A. These data strongly suggest that p300 serves as a bridging protein to connect ElA to promoter-bound YYl for transcriptional activation.

It is possible that the mutant p300 $\mathrm{dl} 10$ is not only defective for binding E1A but also compromised in its ability to function as a transcriptional cofactor. To address this issue, the ability of the carboxy-terminal half of p300 (amino acids 1257-2414) and its mutant derivative containing the same internal deletion (amino acids 1679-1812) as p300 dl10 to regulate transcription was analyzed. Both forms of p300 were fused to the GAL4 DNA-binding domain (amino acids 1-147) and were found to activate GAL4-E1BCAT (data not shown). These data suggested that the carboxy-terminal half of p300 may contain the functional domain for its transcriptional coactivator function, which is not affected by the dl10 deletion mutation. Therefore, the failure of p300 dl10 to activate pP5-60CAT in 293 cells is most likely attributable to its inability to interact with ElA.

YY1 binds to a carboxy-terminal region of p300 distinct from the E1A-binding site

The YY1-interacting domain of $\mathrm{p} 300$ was mapped to its carboxy-terminal region (Fig. 4D,E), which also contains a binding site for ElA (Eckner et al. 1994). To determine whether the YY1-binding site overlaps that of E1A, 
coimmunoprecipitation experiments were performed. The carboxy-terminal half of the p300 protein (BglII ATG, amino acids 1257-2414; Eckner et al. 1994) as well as a derivative containing an internal deletion of amino acids 1737-1809 (BglII ATG dl 30) were obtained through in vitro translation. These two proteins were incubated with extracts prepared from Sf 9 insect cells infected with either wild-type baculovirus or a recombinant expressing YY1. As shown in Figure 7A, both forms of the p300 protein were brought down by $\alpha$-YY1 antibodies (lanes 4,7 ) but not by preimmune antibodies (lanes 5,8). Only background signal was detected when p300 was incubated with extracts prepared from wildtype baculovirus-infected cells (lanes 3,6$)$. In contrast, ElA was shown to interact only with the wild-type but not the mutant p300, as reported (Fig. 7A, lanes 10,13; Eckner et al. 1994), suggesting that YY1 and E1A may bind to different subregions of p300.

\section{YY1/p300 complex is undisrupted in adenovirus- infected HeLa cells}

Biochemically, two outcomes can be envisioned after E1A binds to the YY1/p300 complex: E1A may form a tripartite complex with YY1/p300, or it may disrupt the complex. To begin addressing this issue, the state of the YY $1 /$ p300 complex in adenovirus-infected HeLa cells was examined. HeLa cells were either mock infected or infected with wild-type adenovirus wt300 (Shenk et al. 1980). Five hours postinfection, cells were harvested for preparation of extracts. The extracts were used for immunoprecipitation/Western using $\alpha$-YYl antibodies for immunoprecipitation and $\alpha$-p300 antibodies for Western blotting analysis as described earlier. To demonstrate that ElA proteins were made in infected cells, the extracts were probed with $\alpha$-ElA antibodies. As shown in Figure 7B, large amount of ElA proteins were made in HeLa cells $5 \mathrm{hr}$ postinfection. However, the level of the YY1/p300 complex in vivo is comparable with that in uninfected HeLa cells (Fig. 7B). This observation, together with the fact that YY1 and ElA bind to different regions of p300 (Fig. 7A), is consistent with the notion that E1A and YY1 can bind simultaneously to the same p300 molecules.

\section{Discussion}

In this report we have described findings that uncover a molecular mechanism for the relief of YYl-mediated transcriptional repression by E1A. We began with genetic analyses of ElA domains important for relieving YY1 repression. These studies indicated the importance of p300 and suggested the existence of a YY1/p300 complex in vivo. Consequently, we searched for and identified a YY1/p300 complex in cells using multiple, independent approaches. To unequivocally demonstrate that p300 mediates functional interactions between YYl and E1A, p300 was shown to activate CAT activity through a YYl site in the presence of ElA. In contrast, p300 failed to activate the same CAT reporter plasmid carrying a mutated YY1 site. Furthermore, the p300 mutant unable to bind ElA also failed to activate YY1-mediated transcription. Taken together, our data showed both physical and functional associations among YY1, p300, and E1 A. The functional analyses using p300 cDNA demonstrated directly the role of $\mathrm{p} 300$ in $\mathrm{YY} / \mathrm{ElA}$ interactions, substantiating the genetic as well as biochemical/immuno-

B
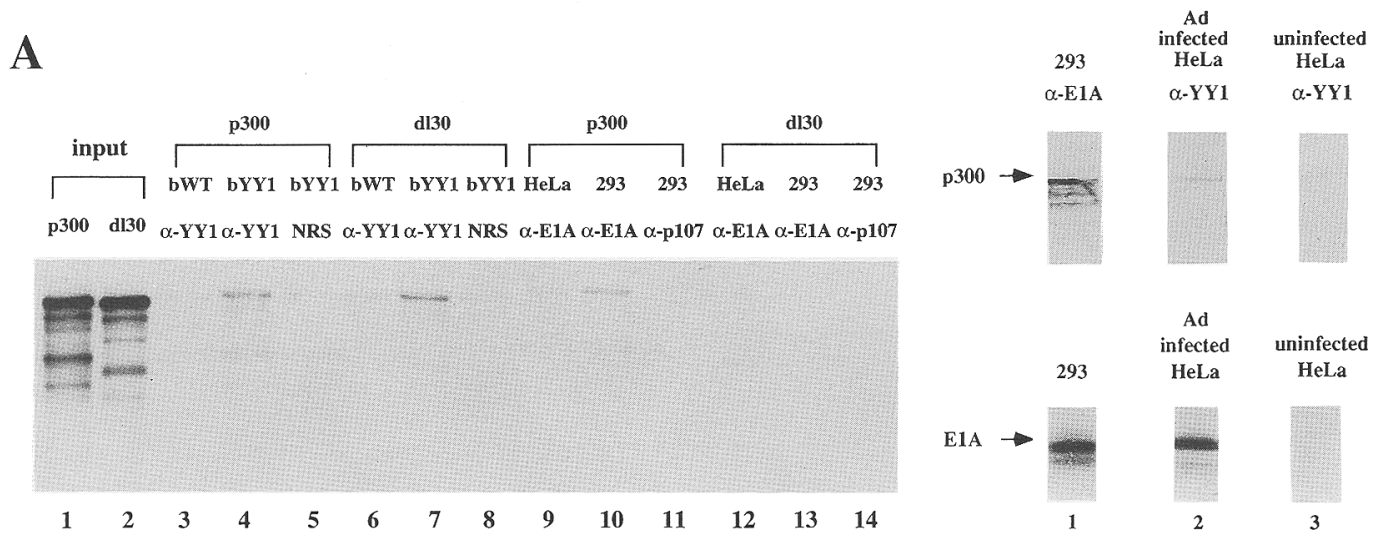

Figure 7. (A) YYl and E1A interact with different subregions of P300 protein. Coimmunoprecipitation of YYl or ElA with both wild-type and mutant p300 was performed. Baculovirus-infected Sf9 cell lysate expressing recombinant YY1 (bYY1) was used as a source of YY1; nuclear extract of human 293 cells was used as a source of ElA. Wild-type baculovirus-infected Sf9 (bWT) cell lysate and HeLa nuclear extract were included as controls. In vitro-translated ${ }^{35}$ S-labeled p300 (BglII ATG, amino acids 1257-2414) and mutant dl30 (BglII ATG, amino acids 1257-24l4 with an internal deletion of amino acids 1737-1809; Eckner et al. 1994) proteins were incubated with various cell lysates and immunoprecipitated with antibodies as indicated. (NRS) Normal rabbit serum. The bound labeled proteins were visualized by autoradiography following SDS-PAGE. Lanes 1 and 2 represent $10 \%$ of each labeled protein used in the binding reactions. $(B)$ ElA does not appreciably alter the level of the YY1/p300 complex in vivo. (Top) p300 immunoblot analysis of immunoprecipitates from adenovirus-infected (lane 2) and uninfected (lane 3) HeLa cells obtained with $\alpha$-YY1 polyclonal antibodies or from 293 cells obtained with $\alpha$-E1A monoclonal antibody M73 (lane 1). The position of p300 is indicated by an arrow at left. (Bottom) E1A immunoblot analysis of the cell lysates used at the top. The position of E1A proteins is indicated by an arrow at left. 
logical assays that implicated p300 in the relief of YY1 repression by E1A.

In a separate study we have shown that removal of as few as $\mathbf{1 7}$ amino acids from the carboxyl terminus of YY1 abolishes its ability to respond to E1A (Lee et al. 1995). The same YY1 mutant also failed to bind p300 in a twohybrid assay in HeLa cells (J.S. Lee and Y. Shi, unpubl.). Therefore, binding of YY1 to p300 correlates with the ability of E1A to modulate the transcriptional activities of YY1. This lends further support to the proposed mechanism that $\mathrm{p} 300$ mediates functional interactions between YYl and ElA.

The possibility that YY1 and ElA interact directly with each other was also investigated, using cloned proteins. These studies showed that a direct interaction between these proteins, if any, appears to be rather weak under our assay conditions. Perhaps more importantly, mapping of domains involved in YY1/ElA direct interactions revealed no correlation with our functional results. When in vitro-translated, ${ }^{35} \mathrm{~S}$-labeled YY1 was incubated with GST-13S E1A beads, only $\sim 0.1 \%$ of the input YY1 was retained by GST-13S E1A. In contrast, the same GST-13S E1A retained $\sim 20 \%$ of in-vitro translated RB proteins under the same assay condition. Significantly, two GST-ElA mutants lacking the aminoterminal region and CR1 of ElA (dl1-28 and dl1-75) captured essentially the same amount of YY1 as did wild-type GST-13S E1A (J.S. Lee and Y. Shi, unpubl.). Functionally, deletion of the amino-terminal region or CRl of ElA was shown to severely impair the ability of E1A to relieve YY1-mediated transcriptional repression (Figs. 2 and 3). Thus, the weak interaction detected between YY1 and E1A in the absence of p300 is not correlated with the functional results. Consistent with the notion that $\mathrm{p} 300$ mediates interactions between $\mathrm{YY} 1$ and E1A, ElA was readily captured by GST-YYl when extracts from 293 cells were used (Lee et al. 1995). The region of YY1 involved in this interaction is essentially the same as that required for interactions with in vitrotranslated p300 (J.S. Lee and Y. Shi, unpubl.). Therefore, based on the evidence presented in this paper, we favor the hypothesis that functionally significant physical interactions between YY1 and ElA in vivo are mediated by cellular proteins such as $\mathrm{p} 300$.

It is not unprecedented that a third protein is involved in the interactions between a viral transactivator and a cellular transcription factor. A classic example is the interaction between the HSV VP16 and the transcription factor Oct-1. After HSV infects permissive cells, the VP16 protein forms a complex with the host cell factor (HCF; Wilson et al. 1993). This interaction will then "prime" VP16 for association with Oct-1 that leads to activation of Oct-1-mediated transcription. In the absence of HCF, VP16 and Oct-1 interact only weakly. The cDNA of HCF encodes a protein of $\sim 300 \mathrm{kD}$, in addition to several smaller polypeptides (Wilson et al. 1993). A comparison between HCF and p300 revealed no significant sequence homology.

The mechanism of the YY1/E1A interaction uncovered by this study reveals interesting features that are distinct from interactions observed between E1A and ATF-2 (Liu and Green 1994). It has been proposed that E1A/ATF-2 interactions are mediated via a promoter targeting region within CR3 of E1A (Lillie and Green 1989; Liu and Green 1994). In the case of YYl, the earlier observation that both 12 S and 13S E1A relieve YY1-mediated repression (Shi et al. 1991) hinted at the possibility that E1A may be brought to the promoter through YY1 in a CR3-independent manner. The data showing that the point mutations abrogating $\mathrm{p} 300$ binding also impaired the ability of $13 \mathrm{~S}$ E1A to activate YY1-mediated transcription is consistent with this possibility (Fig. 3). These results further strengthen the notion that the ability of ElA to bind YY1/p300 is critical for E1A to modulate the activities of $Y Y 1$ and that $C R 3$ alone in vivo cannot direct E1A to DNA-bound YYl.

In the absence of E1A, YY1 functions as a repressor when bound upstream of transcription initiation sites, despite the fact that YYl also contains a potent activation domain at its amino terminus (Lee et al. 1995). This led to the suggestion that the activation domain of YY1 is normally masked under repressing conditions. Consistent with this notion, a mutant YYl with its activation domain replaced by a heterologous one still functions as a repressor. Interestingly, the activation domain is required for E1A to modulate the transcriptional activities of YYl (Lee et al. 1995), although it is not involved in physical interactions with $\mathrm{p} 300$ or E1A. These findings suggest that interaction of E1A with YYl/p300 may cause a conformational change of YY1, resulting in unmasking of the activation domain that engages in subsequent transcriptional activation, either alone (in the case of $12 \mathrm{~S} \mathrm{E} 1 \mathrm{~A}$ ) or in concert with the additional activation domain contributed by CR3 of 13S E1A.

It is worth pointing out that interpretation of the results presented in this paper is complicated by the fact that HeLa cells contain human papillomavirus E6 and E7 products (Schneider-Gadicke and Schwarz 1986). The E7 gene product shares similar functions with ElA, for example, the ability to bind pRB (Dyson et al. 1989). Therefore, if YYl represses transcription via multiple pathways, one of which involves $\mathrm{pRB}$ or its related proteins, it is conceivable that the effect of ElA could be masked by the endogenous E7 in HeLa cells. Regardless, our studies clearly indicate the importance of p300 in the relief of YYl-mediated repression by E1A.

Recently, YY1 has been shown to regulate the activity of the c-fos promoter through a mechanism involving DNA bending (Natesan and Gilman 1993). The orientation of the YYl-binding site determines whether YYl represses or activates the c-fos promoter. Although it is conceivable that E1A may regulate the transcriptional activities of YY1 by influencing its DNA-bending property, we were not able to detect a significant difference in the ability of YY1 to bend DNA in the presence or absence of E1A (Roberson 1990).

The biological functions of the YYl/p300 complex in the absence of E1A are currently unknown and warrant further studies. The interaction between YY1 and p300 seems important for YY1 to function as a repressor, be- 
cause binding of E1A to the YY1/p300 complex affected the repressor activity of YY1. Alternatively, YY1-interacting proteins other than $\mathrm{p} 300$ may be responsible for the repressor activity of YYl. Initial experiments attempting to demonstrate a role for $\mathrm{p} 300$ in YY1-mediated repression by transfection assays in HeLa cells were inconclusive. It is possible that the assay is not sensitive enough to overcome the interference of the endogenous p300. Consistent with this possibility, it was noticed that transfection of p300 into HeLa cells barely raised the overall p300 protein level (J.S. Lee and Y. Shi, unpubl.). It is possible that further work is required to optimize the assay conditions or other approaches may have to be implemented. For instance, a cell line with p300 null mutation, if viable, will be suitable for this purpose. Recently, in a separate study, we noticed that YYl is transcriptionally neutral as a LexA-YYl fusion protein in yeast (J. Koipally and Y. Shi, unpubl.). Experiments are under way to study $\mathrm{YY} 1 / \mathrm{p} 300$ functional interactions in yeast cells.

The cDNA encoding p300 was cloned recently, and the protein was shown to exhibit properties of a transcriptional adaptor (Eckner et al. 1994). It was also found to share significant homology with a CREB-binding protein, CBP (Arany et al. 1994). CBP has been shown to be a cofactor for the CREB transcription factor (Arias et al. 1994; Kwok et al. 1994). YY1 may be the first of many transcription factors that are partners for $\mathrm{p} 300$. The fact that $\mathrm{p} 300$ and $\mathrm{CBP}$ are related raises questions as to whether CBP is also involved in YYl/ElA interaction and whether YYl affects CREB-mediated transcription via $C B P$. Other important issues include the specificity of p300 and CBP, which will be clarified as additional partner proteins for both proteins are uncovered. Both p300 and YY1 have been implicated in cell proliferation and differentiation (Wang et al. 1993; Shrivastava and Calame 1994; Slack et al. 1995); the finding of YYl as a partner protein for $\mathrm{p} 300$ will help identify target genes that p300 may regulate through YY1. Finally, the identification of cellular complexes, such as $Y Y 1 / \mathrm{p} 300$ as a target of ElA, should also help us understand deregulated cell growth and tumorigenesis induced by E1A.

While this paper was under review, two papers from $D$. Livingston and R. Goodman's laboratories (Arany et al. 1995; Lundblad et al. 1995) were published demonstrating that $\mathrm{p} 300 / \mathrm{CBP}$ mediates the interactions between CREB and ElA. Also, substantial evidence has since been obtained in our laboratory suggesting that multiple transcription factors, including CREB and members of the AP-1 family, may utilize p300 as an adaptor protein to interact with E1A (I.-S. Lee and Y. Shi, in prep.). Together with the results presented in this paper, it appears that a theme is emerging that p300 may serve as a common cofactor that chaperons E1A to cellular DNA-binding transcription factors.

\section{Materials and methods}

Plasmids

pGAL4-TKCAT contains five GAL4-binding sites inserted 5 ' of the HSV TK promoter in plasmid pBLCAT2 (Shi et al. 1991).
pGAL4-E1BCAT contains five GAL4-binding sites inserted upstream of the minimal adenovirus E1B promoter, which is linked to the CAT gene (gift of A. Levine, Princeton University, NJ). pGAL4-WT1 was constructed by cloning full-length WT1 cDNA in-frame into the pG4 vector, which expresses the GAL4 (amino acids 1-147) DNA-binding domain. pGAL4-YY1, pP560CAT, and pP5-60/mt2)CAT were described previously (Shi et al. 1991). pCMV-12S and 13S E1A expression vectors were provided by J. Nevins (Duke University, Durham, NC). pCMV-12S dl2-36, dl30-85, dl 120-140, Pm47/Pm124, and frameshift were gifts of M. Mathews (Cold Spring Harbor Laboratory). pCMV13S d12-36 was constructed by using PCR methods with the following primers: 5'-CCCAAGCTTCCACCATGCATTTTGAACCACCTACC-3', and 5'-CCCAAGCTTATGGCCTGGGGCGTTT-3'. 12S E1A amino-terminal point mutants, RG2, HN3, and LS20 (Wang et al. 1993) were subcloned into the pCMVNEOBAM3 expression vector (Kageyama and Pastan 1989). The same set of point mutants and CR1 mutant Pm47 (gift of $M$. Mathews) were introduced into $13 \mathrm{~S}$ background and subcloned into the same expression vector. Wild-type $\mathrm{p} 300$ in the cytomegalovirus- $\beta$ (CMV $\beta$ ) expression vector as well as p300 plasmids for in vitro transcription/translation were described previously (Eckner et al. 1994). The p300 d110 mutant is also in the $C M V \beta$ expression vector and contains an internal deletion removing amino acids $1679-1812$. The three GST-p300 plasmids were constructed by fusing amino acids 1-596, amino acids 744-1571, and amino acids 1572-2370 in-frame with GST moiety in the pGEX-2TK vector. The Cp300/VP16 contains amino acids $871-2377$ of p300 fused to the VP16 activation domain. The Np300/VP16 contains amino acids $1-1257$ of $\mathrm{p} 300$ fused to the VP16 activation domain. The same regions of $\mathrm{p} 300$ without VP16 fusion (Cp300 and Np300) were also cloned into the CMV expression plasmid. All of the above recombinants were verified by sequence analysis.

\section{Cells and transfections}

HeLa or 293 cells were grown on $10-\mathrm{cm}$ dishes in Dulbecco's modified Eagle medium (DMEM) supplemented with 10\% heatinactivated calf serum (HeLa) or fetal calf serum (293). The cells were transfected by the calcium phosphate precipitation method as described (Shi et al. 1991). The total amount of DNA was adjusted with the plasmid pSP72 to be identical for each transfection. Cells were harvested $48 \mathrm{hr}$ after addition of the precipitate. All transfection assays were carried out with at least two independent DNA preparations and were repeated between three and eight times.

\section{CAT assays}

Whole cell extracts were prepared from the transfected cells. CAT activity was assayed as described (Shi et al. 1991) and quantitated with a Beckman LS6500 scintillation counter. Proper amounts of cell extracts were used to measure CAT activity to ensure that the assays were performed within linear range. For all the data presented, at least three independent transfections and CAT assays have been performed.

\section{Immunoprecipitation/Western blotting assays}

HeLa or 293 cells were lysed in lysis buffer 25 mM HEPES /pH 7.0 ), $0.25 \mathrm{M} \mathrm{NaCl}, 2.5 \mathrm{~mm}$ EDTA, $0.5 \mathrm{~mm}$ DTT, $10 \mu \mathrm{g} / \mathrm{ml}$ of leupeptin, $1 \mu \mathrm{g} / \mathrm{ml}$ of pepstatin A, $1 \mu \mathrm{g} / \mathrm{ml}$ chymostatin, 10 $\mu \mathrm{g} / \mathrm{ml}$ of aprotonin, $2 \mathrm{~mm}$ phenylmethylsulfonyl fluoride, and $0.1 \% \mathrm{NP}-40$ ) for $30 \mathrm{~min}$ on ice. Extracts prepared from 293 $\left(3 \times 10^{7}\right)$ and HeLa cells $\left(3 \times 10^{8}\right)$ were incubated with antibodies overnight. Immune complexes were collected with protein A-Sepharose beads, washed with the lysis buffer, and eluted 
with Laemmli sample buffer. Following SDS-PAGE, proteins were transferred to nitrocellulose filters and probed with pooled $\alpha$-p300 antibodies RW105 and RW128 (Eckner et al. 1994).p107 immunoblot analysis was performed by stripping the same blot and probing with $\alpha$-p107 monoclonal antibody SD9 (Dyson et al. 1993), using the Immune Lite II chemiluminescence kit (BioRad).

The converse immunoprecipitation/Western blotting experiments were carried out with essentially the same procedure, except that an $\alpha$-p300 monoclonal antibody RW102 (Eckner et al. 1994) was used for immunoprecipitation and affinity-purified $\alpha-Y Y 1$ polyclonal antibodies were used for Western blotting. For the immunoprecipitation/Western competition experiment, $10 \mu \mathrm{g}$ of purified GST or GST-YYl were incubated with the cell lysates for $1 \frac{1}{2}$ hours before the addition of the antibody RW102.

\section{Analysis of YY1 and p300 interactions with GST fusion proteins}

GST-p300 fusion proteins were induced and purified as described (Lee et al. 1995). HeLa cells were lysed in lysis buffer described above for $30 \mathrm{~min}$ on ice. Extracts prepared from HeLa cells were incubated for $4 \mathrm{hr}$ with various GST-p300 fusion proteins coupled to glutathione-agarose beads (Sigma). The beads were washed with the lysis buffer, and protein complexes were eluted with Laemmli sample buffer. Following SDSPAGE, proteins were transferred to nitrocellulose filters and probed with $\alpha$-YYl monoclonal antibodies.

For the in vitro direct interaction experiment, $5 \mu \mathrm{g}$ of HisYY1 (purified as described previously in Shi et al. 1991) was incubated with $2 \mu \mathrm{g}$ of GST or GST-p300 /amino acids 15722370) coupled to glutathione-agarose beads at $4^{\circ} \mathrm{C}$ for two hr. The beads were then washed extensively with the same lysis buffer described above, and protein complexes were eluted with Laemmli sample buffer. Following SDS-PAGE, proteins were transferred to nitrocellulose filters and probed with affinity-purified $\alpha$-YYl polyclonal antibodies.

\section{In vitro coimmunoprecipitation analysis}

For coimmunoprecipitation of YY1 or ElA with p300, Sf9 cells were lysed with NETN buffer (Kaelin et al. 1991) $36 \mathrm{hr}$ after baculovirus infection. HeLa and 293 cell nuclear extracts were obtained by the Dignam procedure (Dignam et al. 1983). In vitro-translated $\mathrm{p} 300$ proteins were obtained by using the TNT kit (Promega). The p300 template (BgIII ATG) contains amino acids 1257-2414. The mutant dl30 derivative contains essentially the same region of $\mathrm{p} 300$ except for an internal deletion of amino acids 1737-1809, which removes the ElA-interacting domain (Eckner et al. 1994). Immunoprecipitation reactions were performed by incubating ${ }^{35} \mathrm{~S}$-labeled, wild-type, or mutant $\mathrm{p} 300$ proteins with individual cell extracts as indicated in Figure 6A.

\section{Infection of HeLa cells with adenovirus}

HeLa cells were infected with wild-type 300 adenovirus at an m.o.i. of 25 . The cells were harvested $5 \mathrm{hr}$ after infection. Cell lysate preparations used for immunoprecipitation/western experiments were described above.

\section{Acknowledgments}

We thank P. Howley, K. Munger, P. Hinds, A. Lassar, and members of the Shi laboratory for critical reading of the manuscript and for their helpful comments. We are grateful for the gifts of plasmids from M. Mathews, and $\alpha$-pl07 antibody from E. Harlow and N. Dyson (Massachusetts General Hospital East, Charlestown). This work was supported by a grant to Y.S. from the National Cancer Institute, National Institutes of Health (CA58997). R.S was supported by a postdoctoral fellowship from the Medical Research Council of Canada. Y.S. is a recipient of the American Cancer Society Junior Faculty Research Award.

The publication costs of this article were defrayed in part by payment of page charges. This article must therefore be hereby marked "advertisement" in accordance with 18 USC section 1734 solely to indicate this fact.

\section{References}

Arany, Z., W.R. Sellers, D.M. Livingston, and R. Eckner. 1994. ElA-associated p300 and CREB-associated CBP belong to a conserved family of coactivators. Cell 77: 799-800.

Arany, Z., D. Newsome, E. Oldread, D.M. Livingston, and R. Eckner. 1995. A family of transcriptional adaptor proteins targeted by the ElA protein. Nature 374: $81-84$.

Arias, J., A.S. Alberts, P. Brindle, F.X. Claret, T. Smeal, M. Karin, J. Feramisco, and M. Montminy. 1994. Activation of cAMP and mitogen responsive genes relies on a common nuclear factor. Nature 370: 226-229.

Bagchi, S., P. Raychaudhuri, and J.R. Nevins. 1990. Adenovirus E1A proteins can dissociate heteromeric complexes involving the E2F transcription factor: a novel mechanism for E1A trans-activation. Cell 62: 659-669.

Berk, A.J., and P.A. Sharp. 1978. Structure of adenovirus 2 early mRNAs. Cell 14: 695-711.

Berk, A.J., F. Lee, T. Harrison, J. Williams, and P.A. Sharp. 1979. Pre-early adenovirus 5 gene product regulates synthesis of early viral messenger RNAs. Cell 17: 935-944.

Call, K.M., T. Glaser, C.Y. Ito, A.J. Buckler, J. Pelletier, D.A. Haber, E.A. Rose, A. Kral, H. Yeger, W.H. Lewis, C. Jones, and D.E. Housman. 1990. Isolation and characterization of a zinc finger polypeptide gene at the human chromosome 11 Wilms' tumor locus. Cell 60: 509-520.

Chang, L.-S., Y. Shi, and T. Shenk. 1989. Adeno-associated virus P5 promoter contains an adenovirus E1A-inducible element and a binding site for the Major Late Transcription Factor. I. Virol. 63: 3479-3488.

Chrivia, J.C., R.P.S. Kwok, N. Lamb, M. Hagiwara, M.R. Montimy, and R.H. Goodman. 1993. Phosphorylated CREB binds specifically to the nuclear protein CBP. Nature 265: 855-859.

Dignam, J.D., R.M. Lebovitz, and R.G. Roeder. 1983. Accurate transcription initiation of RNA Polymerase II in a soluble extract from isolated mammalian nuclei. Nucleic Acids Res. 11: 1475-1489.

Dyson, N. and E. Harlow. 1992. Adenovirus ElA targets key regulators for cell proliferation. In Cancer surveys (ed. A.J. Levine), pp. 161-195. Cold Spring Harbor Laboratory Press, Cold Spring Harbor, New York.

Dyson, N., P.M. Howley, K. Munger, and E. Harlow. 1989. The human papilloma virus-16 E7 oncoprotein is able to bind to the retinoblastoma gene product. Science 243: 934-937.

Dyson, N., M. Dembski, A. Fattaey, C. Ngwu, M. Ewen, and K. Helin. 1993. Analysis of p107-associated proteins: p107 associates with a form of E2F that differs from pRB-associated E2F-1. J. Virol. 67: 7641-7647.

Eckner, R., M.E. Ewen, D. Newsome, M. Gerdes, J.A. DeCaprio, J.B. Lawrence, and D.M. Livingston. 1994. Molecular cloning and functional analysis of the adenovirus ElA-associated $300-\mathrm{kD}$ protein $(\mathrm{p} 300)$ reveals a protein with properties of a transcriptional adaptor. Genes \& Dev. 8: 869-884.

Fields, S. and O. Song. 1989. A novel genetic system to detect protein-protein interactions. Nature 340: 245-246.

Flanagan, J.R., K. Becker, D. Ennist, S.L. Gleason, P.H. Driggers, B.-Z. Levi, E. Appella, and K. Ozato. 1992. Cloning of a negative transcription factor that binds to the upstream region of Moloney Murine Leukemia Virus. Mol. Cell. Biol. 12: 38-44. 
Graham, F.L., J. Smiley, W.C. Russell, and R. Nairn. 1977. Characteristics of a human cell line transformed by DNA from human adenovirus type 5. I. Gen. Virol. 36: 59-72.

Hariharan, N., D. Kelley, and R.P. Perry. 1991. 8, a transcription factor that binds to downstream elements in several polymerase II promoters, is a functionally versatile zinc finger protein. Proc. Natl. Acad. Sci. 88: 9799-9803.

Harlow, E., P. Whyte, B.R. Franza Jr., and C. Schley. 1986. Association of adenovirus early-region $1 \mathrm{~A}$ proteins with cellular polypeptides. Mol. Cell. Biol. 6: 1579-1589.

Horikoshi, N., K. Maguire, A. Krelli, E. Maldanado, D. Reinberg, and R. Weinmann. 1991. Direct interaction between adenovirus E1A protein and the TATA box binding transcription factor IID. Proc. Natl. Acad. Sci. 88: 5124-5128.

Jelmsa, T.N., J.A. Howe, J.S. Mymryk, C.M. Evelegh, N.F. Cunnif, and S.T. Bayley. 1989. Sequences in E1A proteins of human adenovirus 5 required for cell transformation, repression of a transcriptional enhancer, and induction of proliferating cell nuclear antigen. Virology 171: 120-130.

Jones, N. and T. Shenk. 1979. An adenovinus type 5 early gene function regulates expression of other early viral genes. Proc. Natl. Acad. Sci. 76: 3665-3667.

Kaelin, W.G. Jr., D.C. Pallas, J.A. DeCaprio, F.J. Kaye, and D.M. Livingston. 1991. Identification of cellular proteins that can interact specifically with the T/E1A-binding region of the rebinoblastoma gene product. Cell 64: 521-531.

Kageyama, R. and I. Pastan. 1989. Molecular cloning and characterization of a human DNA binding factor that represses transcription. Cell 59: 815-825.

Kimelman, D., J.S. Miller, D. Porter, and B.E. Roberts. 1985. E1a region of human adenovirus and of the highly oncogenic simian adenovirus 7 are closely related. I. Virol. 53: 399-409.

Kwok, R.P.S., J.R. Lundblad, J.C. Chrivia, J.P. Richards, H.P. Bachinger, R.G. Brennan, S.G.E. Roberts, M.R. Green, and R.H. Goodman. 1994. Nuclear protein CBP is a coactivator for the transcription factor CREB. Nature 370: 223-226.

Lee, J.S., R.H. See, K.M. Galvin, J. Wang, and Y. Shi. 1995. Functional interactions between YYl and adenovirus ElA. $\mathrm{Nu}$ cleic Acids Res. 23: 925-931.

Lee, T.-C., Y. Zhang, and R.J. Schwartz. 1994. Bifunctional transcriptional properties of YYl in regulating muscle actin and c-myc gene expression during myogenesis. Oncogene 9: 1047-1052.

Lee, W.S., C.C. Kao, G.O. Bryant, X. Liu, and A.J. Berk. 1991. Adenovirus ElA activation domain binds the basic repeat in the TATA box transcription factor. Cell 67: 365-376.

Lewis, I.B. and M.B. Mathews. 1980. Control of adenovirus early gene expression: A class of immediate early products. Cell 21: 303-313.

Lillie, J.W. and M.R. Green. 1989. Transcription activation by the adenovirus Ela protein. Nature 338: 39-44.

Liu, F. and M.R. Green. 1990. A specific member of the ATF transcription factor family can mediate transcription activation by the adenovirus E1A protein. Cell 61: 1217-1224.

. 1994. Promoter targeting by adenovirus E1 a through interaction with different cellular DNA-binding domains. $\mathrm{Na}$ ture 368: 520-525.

Lundblad, J.R., R.P.S. Kwok, M.E. Laurance, M.L. Harter, and R.H. Goodman. 1995. Adenoviral ElA-associated protein p300 as a functional homologue of the transcriptional coactivator CBP. Nature 374: 85-88.

Madden, S., D.M. Cook, J.F. Morris, A. Cashler, V. Sukhatme, and F.J. Rauscher III. 1991. Transcriptional repression mediated by the WT1 Wilms tumor gene product. Science 253: 1550-1553.

Montell, C., E.F. Fisher, M.H. Caruthers, and A.J. Berk. 1982. Resolving the functions of overlapping viral genes by site- specific mutagenesis at a mRNA splice site. Nature 295: 380-384.

Morris, G.F., and M.B. Mathews. 1991. The adenovirus E1A transforming protein activates the proliferating cell nuclear antigen promoter via an activating transcription factor site. J. Virol. 65: 6397-6406.

Natesan, S. and M.Z. Gilman. 1993. DNA bending and orientation-dependent function of YY1 in the c-fos promoter. Genes \& Dev. 7: 2497-2509.

Nevins, J.R. 1981. Mechanism of activation of early viral transcription by the adenovirus ElA gene product. Cell 26: 213 230

- 1991. Transcriptional activation by viral regulatory proteins. Trends Biochem. Sci. 16: 435-439.

_- 1992. E2F; a link between the Rb tumor suppressor protein and viral oncoproteins. Science 258: 424-429.

Park, K. and M. Atchison. 1991. Isolation of a candidate repressor/activator, NF-E 1 (YY $1, \delta$ ), that binds to the immunoglobulin $\kappa 3^{\prime}$ enhancer and the immunoglobulin heavy-chain $\mu \mathrm{E} 1$ site. Proc. Natl. Acad. Sci. 88: 9804-9808.

Riggs, K.J., S. Saleque, K.-K. Wong, K.T. Merrell, J.-S. Lee, Y. Shi, and K. Calame. 1993. Yin-Yang-1 activates the c-myc promoter. Mol. Cell. Biol. 13: 7487-7495.

Roberson, E.D. 1990. "Sequence-directed and protein-induced DNA-bending at a locus involved in the E1A responsiveness of the adeno-associated virus P5 promoter." Thesis, Princeton University, NJ.

Ruppert, J.M., K.W. Kinzler, A.J. Wong, S.H. Bigner, F-T. Kao, M.L. Law, H.N. Seuanez, S.J. O'Brien, and B. Vogelstein. 1988. The GLI-Kruppel family of human genes. Mol. Cell. Biol. 8: 3104-3113.

Schneider-Gadicke, A. and E. Schwarz. 1986. Different human cervical carcinoma cell lines show similar transcription patterns of human papillomavirus type 18 early genes. EMBO $/$. 5: 2285-2292.

Shenk, T. and J. Flint. 1991. Transcriptional and transforming activities of the adenovirus ElA proteins. Adv. Cancer Res. 57: 47-85.

Shenk, T., N. Jones, C. Colby, and D. Fowkles. 1980. Functional analysis of adenovinus 5 host range deletion mutants defective for transformation of rat embryo cells. Cold Spring Harbor Symp. Quant. Biol. 44: 367-375.

Shi, Y., E. Seto, L.S. Chang, and T. Shenk. 1991. Transcriptional repression by YY1, a human GLI-Kruppel related protein, and relief of repression by adenovirus E1A protein. Cell 67: $377-388$.

Shrivastava, A. and K. Calame. 1994. An analysis of genes regulated by the multi-functional transcriptional regulator Yin Yang-1. Nucleic Acids Res. 22: 5151-5155.

Slack, R.S., J. Craig, S. Costa, and M.W. McBurney. 1995. Adenovirus $5 \mathrm{ElA}$ induced differentiation of P19 embryonal carcinoma cells requires binding to $\mathrm{p} 300$. Oncogene 10: 19-25.

Wang, H.-G.H., Y. Rikatake, M.C. Carter, P. Yaciuk, S.E. Abraham, Z. Brad, and E. Moran. 1993. Identification of specific adenovirus ElA amino-terminal residues critical to the binding of cellular proteins and to the control of cell growth. $J$. Virol. 67: 476-488.

Whyte, P., N.M. Williamson, and E. Harlow. 1989. Cellular targets for transformation by the adenovirus E1A proteins. Cell 56: $67-75$.

Wilson, A., K. LaMarco, M.G. Peterson, and W. Herr. 1993. The VP16 accessory protein HCF is a family of polypeptides processed from a large precursor protein. Cell 74: 115-125.

Yee, S.P. and P.E. Branton. 1985. Detection of cellular proteins associated with human adenovirus type 5 early region $1 \mathrm{~A}$ polypeptides. Virology 147: 142-153. 


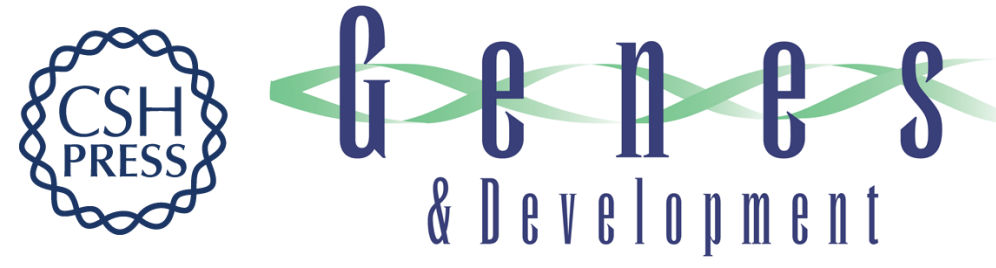

\section{Relief of YY1 transcriptional repression by adenovirus E1A is mediated by E1A-associated protein p300.}

J S Lee, K M Galvin, R H See, et al.

Genes Dev. 1995, 9:

Access the most recent version at doi:10.1101/gad.9.10.1188

References This article cites 53 articles, 19 of which can be accessed free at:

http://genesdev.cshlp.org/content/9/10/1188.full.html\#ref-list-1

License

Email Alerting

Service right corner of the article or click here.

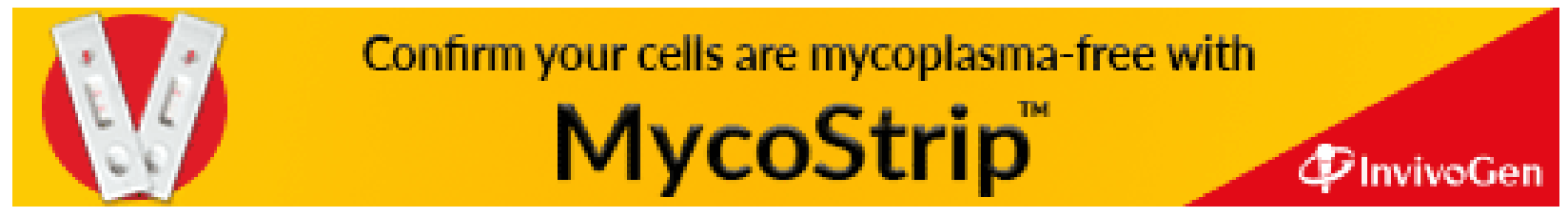

